\title{
Sexually Risky Behavior in College-Aged Students
}

\author{
Carol Caico \\ New York Institute of Technology, New York, USA \\ Email: cac@optonline.net
}

Received 24 March 2014; revised 9 May 2014; accepted 20 May 2014

Copyright (C) 2014 by author and Scientific Research Publishing Inc.

This work is licensed under the Creative Commons Attribution International License (CC BY). http://creativecommons.org/licenses/by/4.0/

\section{(c) (i) Open Access}

\begin{abstract}
Objective: To examine college-aged students' sexual risk taking behavior and their knowledge level. Design: descriptive design participants. Setting: A convenience sample of college-aged students between the ages of $17-25$. Results: Seven hundred and seventy students responded to the survey. Findings revealed that $33 \%$ had sexual intercourse with two to five individuals, and $15.5 \%$ between eleven and twenty sexual partners. $50.9 \%$ had unprotected vaginal intercourse not using condoms and of those $\mathbf{4 5 . 8 \%}$ either do not insist on condom use or only use them occasionally. $\mathbf{2 2 . 1 \%}$ do not insist on using condoms for sexual intercourse and $24.7 \%$ responded that they sometimes insist on condom use. $47.2 \%$ are not worried about getting AIDS. $41.3 \%$ are not concerned with genital lesions. $42.4 \%$ would rate themselves as not being very knowledgeable about sexually transmitted infections. $12.4 \%$ of the females had unintended pregnancies and overall $\mathbf{7 4 . 9 \%}$ would not feel comfortable discussing their sexual activity with their mothers. $58.1 \%$ use alcohol prior to or during sexual intercourse.
\end{abstract}

\section{Keywords}

STD's, STI, Chlamydia, Herpes, Human Papilloma Virus, Trichomonas, HIV

\section{Introduction}

The United States has the highest rate of sexually transmitted diseases (STD's) compared to other countries. The annual direct health care dollars spent within the health system on STD's in the United States is 14.7 billion dollars [1]. Sexually transmitted infections (STI's) continue to be a major public health concern and a significant source of morbidity [2]. Nationally, adolescents are at greater risk than any other age group for contracting STI's, Nearly 3 million United States adolescents acquire an STI every year with almost 62\% occurring in individuals under 25 [2]. Research has demonstrated that sexual risky behavior increases in adolescence and peaks in early adulthood. This behavior leads to an increased number of sexual partners which in turn leads to an increase in 
STI's [3]. College-aged students are at an extremely high risk of contracting STD risk [4]. College students represent unique interest to researchers and wellness program directors as well as policy makers interested in promoting sexual health and wellness in young adults [5]. The CDC (Center for Disease Control) and Healthy People 2020 have addressed adolescent STI's and are targeting gonorrhea and chlamydia with the goal to decreasing these diseases [6].

\section{Literature Review}

The most commonly reported STD's which are an issue for college students in the US are human papilloma virus (HPV), chlamydia, gonorrhea, and genital herpes, trichomoniais and HIV.

Human Papilloma Vurus (HPV) - HPV is a virulent virus and is the most common STD in the US affecting 20 million young men and women between the ages of 15 - 24. The virus spreads rapidly in adolescents and young adults. This is the virus that causes cervical cancer, which is the third most common cause of cancer deaths among women [7]-[9].

Chlamydia-This is the most common reportable bacterial STI in the US. More than 3 million new cases occur annually. It is transmitted though vaginal, anal and oral sex. This is referred to as the silent disease because in the majority of cases, no symptoms are experienced. Chlamydia is responsible for pelvic inflammatory disease in up to $40 \%$ of untreated females [10] [11]. Chlamydia is responsible for infertility in women by scarring the fallopian tubes. Chlamydia can be treated with antibiotics such as azithromycin or doxycyline.

Gonorrhea-Approximately 700,000 new cases are reported annually. This is also contracted through vaginal, oral or anal sex as well as from ejaculation. Symptoms are often mild, and there may be increased vaginal discharge and spotting between periods. This is a serious disease that can also lead to pelvic inflammatory disease and inflammation of the uterine tubes leading to scarring resulting in infertility as well as leading to a higher incidence of ectopic pregnancy (pregnancy outside of the uterus) [12]. Gonorrhea can be treated with antibiotics such as eftriaxone, cefixime, azithromycn or doxycycline. Screening for chlamydia and gonorrhea should be routine annually. The Center for Disease Control and Prevention (CDC) recommends yearly screening for those at risk [13]. There is now evidence of microbial resistance in treating gonorrhea [13].

Herpes-Vaginal or penile herpes causes very painful ulcer-like sores and because it is caused by a virus, there is no cure for viruses and recurrent outbreaks of the sores can occur [14]. Genital herpes is a common, transmissible, recurrent, incurable STI. There are antiviral medications which do not cure this STD, but can decrease the viral load which may decrease the frequency of the outbreaks. The majority of new infections occur in adolescents and young adults [15].

Trichomoniasis-This STD is caused by a parasite and symptoms are production of a frothy green malodorous discharge. This can be treated and the parasites killed. Both partners should be treated with the appropriate antibiotic usually flagyl.

HIV - HIV is still epidemic after 30 yrs since it was first diagnosed. In a survey of young adults aged 19 - 29, it was found that $45 \%$ were never tested for HIV and of those $70 \%$ gave a reason that they did not believe they were at risk [16] [17]. It is estimated that 125.104 persons aged 13 and over were newly diagnosed with HIV infection during the years 2006-2009 and a higher percentage were between the ages of 13 - 29 [18]. Young sexually active individuals frequently request an HIV tests because of their engagement in risky sexual behavior. When HIV was first discovered, it was thought to be only a disease affecting homosexual males. It is being spread by heterosexual intercourse and women are being infected at an alarming rate.

HIV screening can identify many HIV cases, and treatment can be started earlier. Homosexual males, bisexuals and substance abusers should be screened often. All pregnant women are routinely screened for the HIV virus. Although HIV is a virus there are several new combinations of antiviral medications that can effectively reduce the virus and add years to the lives of those infected with HIV [19].

Young adults frequently make decisions that lead to risky behavior due to inadequate comprehension of STD risks and their lack the problem solving skills in order to make good decisions [20]. Due to their ineffective negotiation skills and factors such as poor relationship dynamics many do not use condoms nor due women insist on condom use. When condoms are used correctly there is a reduction in the transmissio of STI's [21]. High risk sexual behavior, such as incorrect use of barrier methods and multiple partner selection are common in this age group [22]. STI's are preventable but rates of many STI's continue to increase particularly among the young. At risk individuals may be at risk because of lack of knowledge about STI's and by not using condoms [23]. The 
problems with most STI's is that they can be present with no symptoms, therefore they can be passed on during sexual intercourse without the partner realizing that they contracted a disease [22]. Nearly 50\% of STI's occur in adolescents and young adults between the ages of 15 and 24. Behavioral factors especially in young women is having multiple sexual or new partners and not using condoms [12]. Other factors such as binge-drinking occur in both young men and women and may lead to increased risky sexual behavior and unintended pregnancies due to decreased inhibitions and moral judgment [24]. Substance abuse and binge-drinking lead to other sexual risky behaviors including multiple sexual partners. Studies have highlighted that unintended pregnancies result from decreases use of condoms and contraceptive use [10].

\section{Summary}

There are many sexually transmitted infections that can result in life altering consequences to young individuals. A knowledge deficit in the sexually active young population may play a part in the continued risky sexually behavior demonstrated, or possibly just the belief that they are invincible [25].

The aim of this research was to examine college-aged student's risky sexual practices, and identify knowledge gaps regarding particular STD's and how they are transmitted.

\section{Method}

\subsection{Design, Setting, and Sample}

This study was an exploratory descriptive design. A convenience sample was selected from a population of male and female students from a private suburban college in the Mid-Atlantic region of the United States. Subjects were recruited by e-mail invitation sent to the students via a secure anonymous website. Inclusion criteria were students who were sexually active and were between the ages of 17 and 25. The population statistics of students registered at the college were 1279 female students and 1948 male students between the ages of 17 and 25. Data collection was over a 4 month period from mid January to mid May 2012, N = 770.

\subsection{Protection of Human Subjects}

The study was approved by the college's institutional review board (IRB). Because the study used an on-line data collection via a monkey survey, total anonymity was maintained. An explanation of the study was provided to the students and participation was completely voluntary. Consent was implied if the students chose to participate, although and informed letter of consent was included with the on-line information. Included was information regarding the researcher contact information. The request to participate assured the students that complete anonymity and confidentiality would be maintained. Participants were then directed to the actual survey. There were no link to the student's e-mails. There was no stipend or any method of coercion for students to participate. Participation was totally voluntary and it was clearly stated only student's who are or have been sexually active are to participate.

\subsection{Instrument}

The survey was designed as a self-administered questionnaire which was converted to a web-based format. There were 46 items on the survey designed to elicit information about student's sexual history, demographics, sexual practices and knowledge based of many of the sexually transmitted diseases. The demographic questions were related to gender, age, race, sexual orientation, how many current sexual partners and the school at the college that the student was enrolled in. The items on the survey were an adaptation of questions from three published questionnaires with proven reliability and validity from a book of sexually related measures [9].

The questions taken from the three published surveys were used verbatim, and were not altered for this study. Six items on the survey addressed respondents' history regarding race, age, ethnicity, sexual orientation, number of current sexual partners and the course of study the student was enrolled in at the college. The instrument contained 6 questions with a range of answers and students were instructed to answer which would apply to them; there were also 15 Likert-type questions with 4 choices; and 19 true and false questions. The questionnaire was administered a group of students to determine if the questions were easily understood and all that all questions were questions answered, which determined content validity and further reliability that the question chosen from the three surveys addressed the information for the study. 


\subsection{Procedure}

An announcement was sent via e-mail to all the students enrolled in the college requesting participation in the study. Although the college is global, only the campus located in the Mid-Atlantic coast was included. The announcement described the purpose of the study, including the criteria for voluntary participation and an explanation that the study would include an anonymous survey. The first e-mail included a link directing the students to the secure website where the survey could be accessed. The e-mail was sent out each week to remind students about the study and requesting their participation. This was done to assure an adequate sample size for the research. Completed surveys were downloaded directly into the survey monkey which the researcher had access only to the answers and the number of students who participated.

\subsection{Demographic Findings}

There were 3229 students at the participating college, 1279 females and 1948 males between the ages of 17 and 25 . From this population $16 \%$ of males and $33.5 \%$ of females responded to the study with a total of 770 participants. Although there were no statistics on sexually active students at the college and the assumption is that statistically most college students enrolled are sexually active. A study done at a large northeastern community college evaluating a sexuality course found that over $80 \%$ of the students had sexual intercourse [9]. The participants ethnicity and race breakdown was $46.0 \%$ Caucasian, $16.3 \%$ Asian, $11.4 \%$ Hispanic/Latino, 16.8\% were African American. 89.2\% were heterosexual, 5.7\% were homosexual and 4.3\% were bisexual. 81.6\% currently have one sexual partner, $8.8 \%$ have had two past partners, $4.3 \%$ had between three and five partners and $5.2 \%$ have had greater than 5 partners. The results by programs at the college were $31.3 \%$ were in the School of Health Profession, 23.2\% were the School of Arts and Sciences, 15.4\% were from the School of Engineering, 11.3\% were from the School of Architecture and 19.0\% were from other Programs.

\subsection{Survey Results}

$33.5 \%$ of respondents have had sexual intercourse with between two and five people; $15.5 \%$ between six and ten; 9.5\% between eleven and twenty; and $7.1 \%$ over twenty. 37.8\% have sexual intercourse less than once a week, $31.4 \%$ have intercourse between one and two times a week and only $6.1 \%$ have intercourse between five and seven times per week. 58.3\% responded that their last sexual encounter was less than a week ago and of those, over half had $50.9 \%$ had unprotected vaginal sex and $56.8 \%$ had unprotected oral sex. $21.1 \%$ never insist on condom use and $24.0 \%$ sometimes insists. $47.2 \%$ of these sexually active students never worry about getting AIDS and 27.2 worry about it sometimes. $41.3 \%$ do not examine partner for sores, cuts or abrasions in the genital area. $27.8 \%$ engage in anal intercourse. $58.1 \%$ of this student population drink alcohol prior to or during sexual intercourse.

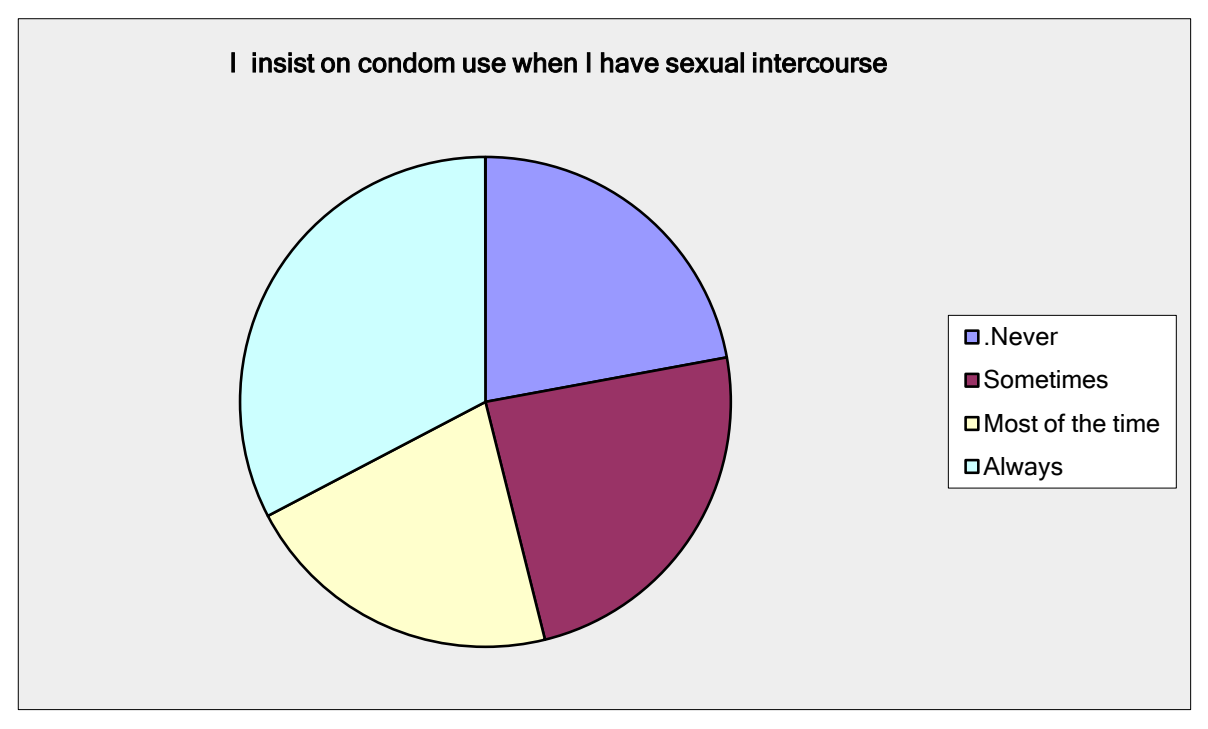




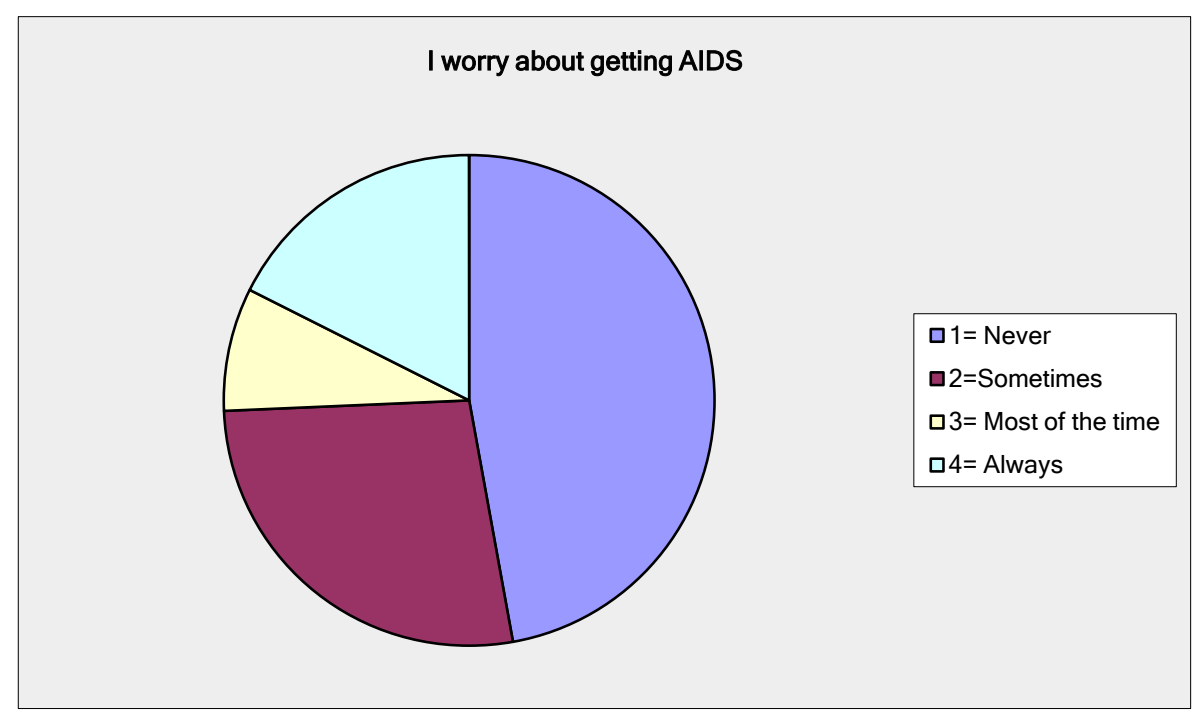

I drink alcoholic beverages prior to or during sexual intercourse

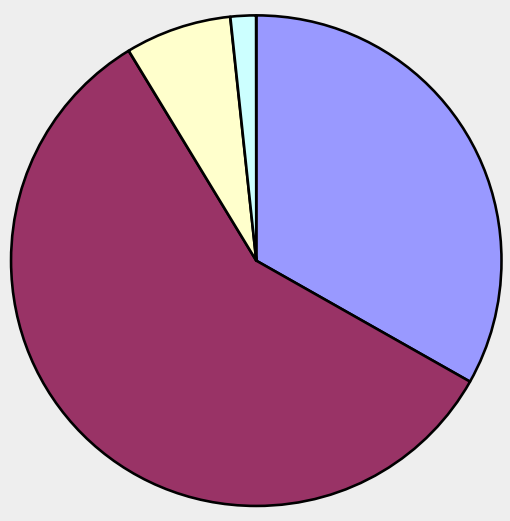

口1=Never

$\square 2=$ Sometimes

口3=Most of the time

口4= Always

\subsection{Survey Results: Knowledge}

To indicate the students' knowledge about STD's, a question regarding since sex causes sexually transmitted infections (STI's) and would they change their sexual practices to avoid contracting STD's demonstrated that: 51\% would not consider abstinence to avoid STI's. The true and false answers regarding their knowledge of particular STI's, such as Chlamydia, human papilloma virus (HPV), genital herpes, and HIV were answered with over 80\% correctly, although $31.9 \%$ did not know that untreated chlamydia could caused female infertility. 14.3\% answered that they have been treated for an STD. The females had a $12.5 \%$ rate of unintended pregnancy. $42 \%$ would not rate themselves as being very knowledgeable about sexually transmitted infections, which is a significant amount who admit to a lack of knowledge about STD's.

\subsection{Survey Results: Perception}

$62.1 \%$ of the study population wonder during sex what the other person thinks of them. $83.3 \%$ do feel uncomfortable in sexual situations, yet $74.4 \%$ would not share their sexual activity with their mothers.

\subsection{Limitations}

Collecting sensitive data has inherent limitations such as participants not being totally truthful. The true and 
false questions may have given the participant and easy format for them to answer correctly which was the format for several of the STI questions, yet $42 \%$ rated themselves as not being very knowledgeable about STI's. Just using the total number of students enrolled in the college to determine the percentage of students who participated in the study does not demonstrate an actual percentage as only the students who were sexually active were requested to participate and there may be many more sexually active students who did not participate even though the sample size of 770 participants was good.

The research included students from the school of Health Profession who have courses in health topics including learning about implications, and treatment of STD's. This may have skewed results. Perhaps they should have been excluded from the study. If the students of the Health Professions were excluded, the knowledge deficit regarding STI's may have been much higher.

\section{Discussion}

The findings from this study are more comprehensive than other studies done one similar topics. A study done by Brown [26] looked at alcohol use and partner type as contributing factors in risky sexual behavior and found unprotected sex was 39\% and 32\% used alcohol. Compared to the current study which demonstrated an $11.9 \%$ higher unprotected sex rate and a 26.2\% higher use of alcohol prior to sex. Another comparison is with a study done on several campuses in California which has a high incidence of no condom use of approximately $48.5 \%$ versus the current study had a $2.4 \%$ increase. Most studies look only at one or two issues such as contracting each specific STI's [27]. Another study done by Jones and Haynes looked at young people's knowledge of STD's and found similar results in this study in that there is a low knowledge about contracting HIV and a low concern of contracting this STD.

The study was done in the UK [28] which confirms that young people worldwide take sexual risks. Findings from this study indicate that at one college, there is an increased sexually activity level in the younger population and use of condoms is relatively low, increasing risky sexual behavior.

Risk of contracting STI's does not alter the rate of condom use or the number of sexual partners. A great percentage $74.5 \%$ never or sometimes worry about contracting AIDS even with the low condom use. The fact that 31.3\% of the students were from the School of Health Professions may have accounted for a better understanding of certain sexually transmitted infections. This study indicates that many young adults between the ages of 17 and 25 place themselves at unnecessary sexual risks and lack knowledge sexually transmitted infections and the potential lifelong consequences of many of the STD's. The results closely correlate to young women who are being seen in private GYN offices. It is found that adolescents and young women often do not use condoms consistently. These young patients often request “Can you test me for all STD's and for an HIV test?” Sexual activity occurring starting at a younger age and a history of multiple past partners is common. These findings have very important implications to society. In study of risky adolescent sexual behavior the unintended childbearing was 38\% and 19 million STD cases are diagnosed annually. The cost of these unintended births and ST's are very high [29]. There is still a gap in educating the young about the impact of unprotected sex and the potential lifelong implication of contacting STD's education must start in all middle schools, be taught again in high school and included in college education. It is apparent through the literature search and the results of this study that constant reinforcement of this material is necessary. Nurse Practitioners especially, and all health care providers who care for adolescent and young adult males and females must direct their efforts to screen for all STD's and education during their health visits aimed at increasing knowledge about sexually risky behavior, how STD's are transmitted and how to protect oneself.

Workshops in high school and colleges or in community center where young people congregate would be a perfect opportunity for nurse practitioners and all health care providers and educators across the country to address this epidemic of continued risky sexual behavior. Practitioners should volunteer in their communities to address this serious problem. Since nurse practitioners are trusted providers they must continue to reinforce and educate about the dangers of risky sexual behavior. The older population is facing an increase in sexually transmitted infections as divorce or widowhood places them back in the sexual arena. This is a huge social problem that needs addressing at all levels. A controlled research study which provided a seminar about sexually transmitted infections, safer sex, decision making. Sexual practices were assessed at baseline and again in 3 months to the intervention group of college students. The students who received the education reported increased sexual abstinence in the males but no change in condom uses and the women reported no change in abstinence but an 
increase in condom use [30].

To change the risky sexual behavior education needs to be continually reinforced with seminars held during the college years. Education should also be a priority with these adolescent and young adults during their health exams and when seen in college health departments. Every opportunity to relay the seriousness of sexually risky behavior and the long term health implications should be implemented.

\section{Future Research}

Suggested future research should be a correlation study comparing age, ethnicity, sexual preference and with degree of sexually risky behavior. Students who are enrolled in health related degree programs and may be very knowledgeable should be eliminated since it may skew the actual results. Other research of interest would be to do a study on the older population and the risky sexual behavior particularly the divorced, widowed or those who are sexually active outside of their marriages and compare finding to the same study done on a younger sexually active population.

\section{References}

[1] Chesson, H.W., Gift, T.L., Owusu-Edusel, K., Tao, G., Johnson, A.P. and Kent, C.K. (2011) A Brief Review of the Estimated Economic Burden of Sexually Transmitted Diseases in the United States: Inflation-Adjusted Updates of Previously Published Cost Studies. Sexually Transmitted Diseases, 38, 889-891. http://dx.doi.org/10.1097/OLQ.0b013e318223be77

[2] Fantasia, H.C., Fontentot, H.B., Sutherland, M. and Harris, A.L. (2011) Sexually Transmitted Infection in Women. Nursing for Women's Health, 15, 46-57. http://dx.doi.org/10.1111/j.1751-486X.2011.01610.X

[3] Yager, A.M. and O’Keefe, C. (2012) Adolescent Use of Social Networking to Gain Sexual Health Information. The Journal for Nurse Practitioners, 8, 294-298. http://dx.doi.org/10.1016/j.nurpra.2012.01.016

[4] Pflieger, J.C., Cook, E.C., Niccolai, L.M. and Connell, C.M. (2013) Racial/Ethnic Differences in Patterns of Sexual Risk Behavior and Rates of Sexually Transmitted Infections among Female Young Adults. American Journal of Public Health, 103, e1-e7. http://dx.doi.org/10.2105/AJPH.2012.301005

[5] McCave, E., Azulay Chertok, A., Winter, V. and Hale, Z. (2013) Sexual Health Behaviors in Random Sample of Students at a Mid-Atlantic University: 2010-2011. Journal of Community Health, 38, 310-319. http://dx.doi.org/10.1007/s10900-012-9616-2

[6] Center for Disease Control (2010) Healthy People 2020.

[7] Carter, J.S. and Downs, L.S. (2011) Cervical Cancer Tests and Treatment. The Female Patient, 36, 34-37.

[8] Caico, C. and Driscoll, D. (2009) The Adolescent Pelvic Examination: Challenges, Critical Issues and an Opportunity to Protect Your Patients against HPV. Women's Healthcare, 8, 20-24.

[9] Fisher, D., Davis, C.M., Yarber, W.L and Davis, S.L. (2011) Handbook of Sexuality-Related Measures. 3rd Edition, Sage Publications, Routledge.

[10] Friedman, A.L. and Bloodgood, B. (2010) “Something We’d Rather Not Talk about”: Findings from CDC Exploratory Research on Sexually Transmitted Disease Communication with Girls and Women. Journal of Women's Health, 19, 1823-1831. http://dx.doi.org/10.1089/jwh.2010.1961

[11] Hicky, M. (2009) Female College Student's Knowledge, Perceptions and Use of Emergency Contraception. JOGNN, 38, 399-405. http://dx.doi.org/10.1111/j.1552-6909.2009.01035.X

[12] Stamm, C., Miranda, R.H., McGregor, J.A. and Idsog, C.M. (2011) An Evidence-Based Approach to Managing Common STI's in Adolescents. Contemporary OB-GYN, 43-51.

[13] Kieliszek, K. (2011) Trends in Microbial Resistance: Treating Neisseria Gonorrhea Infection. American Journal of Nurse Practitioners, 15, 8-12.

[14] Keefe, A. (2012) Managing Genital Herpes and Minimizing the Discomfort. Nurse Prescribing, 10, 326-330.

[15] Mansouri, R. and Santos, X.M. (2013) Sexually Transmitted Infections in Adolescents. Contemporary OB/GYN, 58, 46-50.

[16] Mojola, S.A. and Everett, B. (2012) STD and HIV Risk Factors among U.S. Young Adults: Variations by Gender, Race, Ethnicity and Sexual Orientation. Perspectives on Sexual and Reproductive Health, 44, 125-132. http://dx.doi.org/10.1363/4412512

[17] Hoppel, A.M. (2012) HIV: Still Epidemic after 30 yrs. Clinician Reviews, 22, 1,11,13,14,33.

[18] Hernandez, A.L., Prejean, J., Doshani, M., et al. (2012) Previous HIV Testing among Adults and Adolescents Newly 
Diagnosed with HIV Infection-National HIV Surveillance System 18 Juristictions, United States, 2006-2009. Morbidity and Mortality Weekly Report, 61, 441-445.

[19] Eaton, D.K., Kann, L., Kinchen, S., Shanklin, S., Flint, K.H., Hawkins, L., Harris, W.A., Lowry, R., McManus, T., Chyen, D., Wjitle, L., Lim. C. and Weschler, H. (2012) Youth Risk Behavior Surveillance United States 2011. MMWR, 6, 1-56.

[20] Patel, V.L., Yoskowitz, A. and Kaufman, D.R. (2007) Comprehension of Sexual Situations and Its Relationship to Risky Decisions by Young Adults. AIDS Care, 19, 916-922. http://dx.doi.org/10.1080/09540120701203303

[21] East, L., Jackson, D., O’Brien, L. and Peters, K. (2010) Condon Negotiation: Experiences of Sexually Active Young Women. Journal of Advanced Nursing, 67, 77-85. http://dx.doi.org/10.1111/j.1365-2648.2010.05451.x

[22] Samkange-Zeeb, F.N., Spallek, L. and Zeeb, H. (2011) Awareness and Knowledge of Sexually Transmitted Diseases (STD's) among School-Going Adolescents in Europe: A Systematic Review of Published Literature. BMC Public Health, 11, 1-12. http://dx.doi.org/10.1186/1471-2458-11-727

[23] Picot, J., Shepherd, J., Kavanagh, J., Cooper, K., Harden, A., Barnett-Page, E., Jones, J., Clegg, A., Hartwell, D. and Frampton, G.K. (2012) Behavioural Interventions for the Prevention of Sexually Transmitted Infections in Young People Aged 13-19 Years: A Systematic Review. Health Education Research, 27, 495-512. http://dx.doi.org/10.1093/her/cys014

[24] Weeder, S.K. (2011) Binge Drinking and Disordered Eating in College Students. Journal of the Academy of Nurse Practitioners, 23, 33-41. http://dx.doi.org/10.1111/j.1745-7599.2010.00568.X

[25] Scott, M.E., Wildsmith, E., Welti, K., Ryan, S., Schelar, E. and Steward-Streng, N.R. (2011) Risky Adolescent Sexual Behavior and Reproductive Health in Young Adulthood. Perspectives on Sexual and Reproductive Health, 43, 110-118. http://dx.doi.org/10.1363/4311011

[26] Brown, J. (2007) Alcohol Use, Partner Type, and Risky Sexual Behavior among College Students: Findings from an Event-Level Study. Addictive Behaviors, 32, 2940-2952. http://dx.doi.org/10.1016/j.addbeh.2007.06.011

[27] Trieu, S.L., Bratton, S. and Marshak, H.H. (2011) Sexual and Reproductive Health Behaviors of California Community College Students. Journal of American College Health, 59, 744-750. http://dx.doi.org/10.1080/07448481.2010.540764

[28] Jones, N.A. and Haynes, R. (2006) The Association between Young People's Knowledge of Sexually Transmitted Diseases and Their Behavior: A Mixed Methods Study. Health Risk and Society, 8, 293-303. http://dx.doi.org/10.1080/13698570600871851

[29] Fontenot, H. and Morelock, N. (2012) HPV in Men Is a Women's Health Issue. Nursing for Women's Health, 15, 57-66. http://dx.doi.org/10.1111/j.1751-486X.2012.01701.x

[30] Turner, J.C., Korpita, E., Mohn, L. and Hill, W.B. (1993) Reduction in Sexual Risk Behaviors among College Students Following a Comprehensive Health Intervention. Journal of American College Health, 41, 187-193. http://dx.doi.org/10.1080/07448481.1993.9936324 


\section{Questionnaire Used in Study}

\section{Your Personal Characteristics}

1. What is your gender?

O Male

O Female

2. How old are you

3. Which racial/ethnic category best describes you?
O African American
O Caucasian
O Asian American
O Hispanic/Latino/Latina
O Native American
$\mathrm{O}$ Other

Please specify

4. Which sexual orientation category best describes you?
O Heterosexual
O Homosexual
O Bisexual
O Other

$$
\text { Please specify }
$$

5. How many sexual partners do you currently have?

\section{Sexual Behavior Questionnaire}

Please indicate the following questions with the letter that best fits your answer.

1. How many individuals have you had sexual intercourse with?
a. None
b. Only one
c. Between two and five
d. Between six and ten
e. Between eleven and twenty
f. Over twenty

2. How many times a week do you engage in sexual intercourse?
a. Less than one
b. Between one and two
c. Between three and four
d. Between five and seven
e. More than seven

3. When you engage in sexual intercourse or other intimate sexual acts, which of the following reasons best describes your motivation?
a. I want the physical release
b. I want to show my love for my partner
c. I am afraid my partner will leave me if I don’t 
4. How long ago was your last sexual encounter?
a. Less than a week ago
b. Between one week and three months ago
c. Between three and six months ago
d. Between six months and one year ago
e. More than a year ago

5. On this last occasion what kinds of sex did you have? (answer all that apply)
a. Unprotected vaginal sex
b. Vaginal sex with a condom
c. Unprotected anal sex
d. Anal sex with a condom
e. Oral sex

6. If you had heterosexual vaginal sex on this occasion, did you use a form of contraception? (Please answer all that apply)
a. The condom
b. The pill
c. The diaphragm or cervical cap
d. IUD
e. Spermicidal sponge or creams
f. The rhythm (calendar method)
g. Withdrawal method
h. Other (please specify)
i. None

Below is a list of questions. Please read each statement and respond by indicating your degree of use of these practices.
$1=$ Never
2 = Sometimes
$3=$ Most of the time
$4=$ Always

7. I insist on condom use when I have sexual intercourse.

8. I worry about getting AIDS.

9. I engage in sexual intercourse on the first date.

10. I engage in oral sex without using protective barriers.

11. I insist on examining my sexual partner for sores, cutsor abrasions in the genital area.

$\begin{array}{llll}1 & 2 & 3 & 4\end{array}$

12. If swept away in the passion of the moment, I have sexual intercourse without using a condom.

13. I engage in anal intercourse.

14. It is difficult for me to discuss sexual issues with my sexual partner.

15. If my partner insists on having sexual intercourse without a condom, I refuse to have sexual intercourse.

16. I have sexual intercourse with someone who I know is bisexual or gay.

$\begin{array}{llll}1 & 2 & 3 & 4\end{array}$

17. I drink alcoholic beverages prior to or during sexual intercourse.

$\begin{array}{llll}1 & 2 & 3 & 4\end{array}$

$\begin{array}{llll}1 & 2 & 3 & 4\end{array}$

Answer the following questions based on:
1 = Strongly agree
2 = Agree
$3=$ Disagree
$4=$ Strongly disagree

18. How one uses their sexuality has nothing to do with STD's.

19. Changing one's sex habits is necessary once the presence of an STD is known.

$\begin{array}{llll}1 & 2 & 3 & 4\end{array}$

20. The change of an STD would not stop me from having sex.

$\begin{array}{llll}1 & 2 & 3 & 4\end{array}$

21. I like the idea of sexual abstinence (not having sex) as the best way of avoiding STD's. 
Answer the following questions as True or False.

22. Half the people in the US will acquire at least one STD by age 35. True False

23. About one in 10 sexually active youth have a sexually transmitted infection. True False

24. Vagina infections like trichomoniasis can not be transmitted to males. True False

25. Human papilloma virus (HPV) is the most common STD in the US. True False

26. The majority of females with Chlamydia do not have any detectable symptoms. True False

27. All bacterial STD can be cured with pennicillin. $\quad$ True False

28. HPV accounts for $90 \%$ of cervical cancer. $\quad$ True False

29. Herpes is only infectious when there are open sores. $\quad$ True False

30. Heterosexual females and males are at a little risk for AIDS. $\quad$ True False

31. The most common cause of infertility among US females is Chlamydia infections. True False

32. A condom reduces the quality of sex so much that it is better not to use one at all. True False

33. Contraceptives ruin the spontaneity of sex. True False

Answer the following questions with Yes or No.

34. Have you had or ever been treated for an STD

35. For females: Have you ever had an unintended/unwanted pregnancy?

Yes No

36. Do you feel uncomfortable in sexual situations?

Yes

No

37. I wonder during sex what the other person thinks of me.

Yes

No

38 Would you rate yourself as very knowledgeable about sexually transmitted infections?

Yes

No

39. Would you feel comfortable sharing your sexual activity with your mother?

Yes

No

40. Were you ever in a situation where sex was forced on you when you did not consent?

Yes

No

Yes

No 